undertaking or recommending couple counselling, and better links with specialist agencies.

Medical administration services should ensure that doctors have access to debriefing; supervision; and legal, police, and welfare agencies. When such assistance is in place doctors will feel better supported and more confident to engage with this critical underlying issue affecting their patients' health and wellbeing.

We thank the North West Melbourne and Central Highlands divisions of general practice for their support and involvement and all the general practitioners who generously gave their time to contribute to the study.

Contributors: See bmj.com

Funding: This research was carried out as part of the doctoral scholarship programme at the National Centre for Epidemiology and Population Health, Australian National University, in collaboration with La Trobe University. This paper was written up by AT as a staff member at CSMCH, La Trobe University.

Competing interests: None declared.

Ethical approval: Human ethics committee at Australian National University.

1 Eisenstat SA, Bancroft L. Domestic violence. N Eng J Med 1999;341:88692.

2 Hegarty K, Bush R. Prevalence and associations of partner abuse in women attending general practice: a cross sectional survey. Aust NZ J Public Health 2002:26:437-42.

3 Oriel KA, Fleming MF. Screening men for partner violence in a primary care setting: a new strategy for detecting domestic violence. J Fam Pract 1998:46:493-8.

4 Webb E, Shankleman J, Evans MR, Brooks R. The health of children in refuges for women victims of domestic violence: cross sectional descriptive study. BMJ 2001;323:210-3.
5 Ferris LE, Norton P, Dunn EV, Gort EH. Clinical factors affecting physician's management decisions in cases of female partner abuse. Fam Med 1999;31:415-25.

6 Richardson J, Coid J, Petruckevich A, Chung WS, Moorey S, Feder G. Women who experience domestic violence and women survivors of childhood sexual abuse: a survey of health professionals' attitudes and clinical practice. BrJ Gen Pract 2001;51:468-70.

7 Sassetti M. Domestic violence. Primary Care 1993;20:289-305.

8 Wathen NC, MacMillan HL. Interventions for violence against women: scientific review. JAMA 2003;289:589-600.

9 Yin R. Case study research: design and methods. Second ed. California: Sage, 1994:171. (Applied Social Methods Series, vol 5.)

10 Strauss A, Corbin J. Basics of qualitative research: grounded theory procedures and techniques. Newbury Park, CA: Sage Publications, 1990.

11 American Medical Association diagnostic and treatment guidelines on domestic violence. Arch Fam Med 1992;Sept(1):39-47.

12 Adams D. Guidelines for doctors on identifying and helping their patients who batter. J Am Med Womens Assoc 1996;51:123-6.

13 Mintz HA, Cornett FW. When your patient is a batterer: what you need to know before treating perpetrators of domestic violence. Postgrad Med 1997;101:219-28.

14 Ferris LE, Norton PG, Dunn EV, Gort EH, Degani N. Guidelines for managing domestic abuse when male and female partners are patients of the same physician. JAMA 1997;278:851-7.

15 Edleson J. Domestic violence and children. Future Child 1999:9(3).

16 Hegarty KL, Taft AJ. Overcoming the barriers to disclosure and inquiry of partner abuse for women attending general practice. Aust NZ J Public Health 2001;25:433-7.

17 Gerbert B, Abercrombie P, Caspers N, Love C, Bronstone A. How health care providers help battered women: the survivor's perspective. Women Health 1999;29:115-35.

18 Bensing JM, Van Den Brink-Muinen A, De Bakker D. Gender differences in practice style: a Dutch study of general practitioners. Med Care 1993;31:219-29.

19 Brandt Jr EN. Curricular principles for health professions education about family violence. Acad Med 1997;72(1, suppl):S51-8.

20 Warshaw C. Intimate partner abuse: developing a framework for change in medical education. Acad Med 1997;72(1, suppl):S26-37.

11 in 1 .

and anasis of how the identification of victims. Ann Intern Med 1999;131:578-84.

(Accepted 22 December 2003)

doi $10.1136 /$ bmj.38014.627535.0B

\title{
Association between depression and abuse by partners of women attending general practice: descriptive, cross sectional survey
}

Kelsey Hegarty, Jane Gunn, Patty Chondros, Rhonda Small

\begin{abstract}
Objective To explore the association between depression and physical, emotional, and sexual abuse by partners or ex-partners of women attending general practice.

Design Descriptive, cross sectional survey.

Setting 30 general practitioners in Victoria, Australia.

Participants 1257 consecutive female patients.

Main outcome measures Some type of abuse in an adult intimate relationship (composite abuse scale), depression (Beck depression inventory or Edinburgh postnatal depression scale), and physical health (SF-36).

Results 18.0\% (218/1213) of women scored as currently probably depressed and $24.1 \%(277 / 1147)$ had experienced some type of abuse in an adult intimate relationship. Depressed women were significantly more likely to have experienced severe combined abuse than women who were not depressed after adjusting for other significant sociodemographic variables (odds ratio 5.8, 95\% confidence interval 2.8
\end{abstract}

to 12.0). These variables included not being married, having a poor education, being on a low income, being unemployed or receiving a pension, pregnancy status, or being abused as a child.

Conclusion Physical, emotional, and sexual abuse are strongly associated with depression in women attending general practice. Doctors should sensitively ask depressed women about their experiences of violence and abuse in intimate relationships. Research into depression should include measures of partner abuse in longitudinal and intervention studies.

\section{Introduction}

Women experience depression about twice as much as men. ${ }^{1}$ This difference may be accounted for by women experiencing greater poverty, differing social roles and sex discrimination, more negative life events, and violence and abuse. ${ }^{1}$ A meta-analysis on the prevalence of mental health problems among women with a history of violence from a partner found that compared with women who had not been abused just
Editorial by Ferris and $\mathrm{p} 618$

Department of General Practice, University of Melbourne, Vic 3053, Australia Kelsey Hegarty senior lecturer Jane Gunn associate professor Patty Chondros lecturer

Centre for the Study of Mothers and Children's Health, La Trobe University, Melbourne, Vic 3053, Australia Rhonda Small senior research fellow Correspondence to: K Hegarty k.hegarty@ unimelb.edu.au 
under a half of the abused women had clinical depression. ${ }^{2}$ Data on this subject are limited in the primary care setting. ${ }^{3}{ }^{4}$ We therefore explored the association between depression and different types of abuse by a partner in women attending general practice.

\section{Methods}

We stratified general practitioners who had previously volunteered for a women's health education programme according to whether their practices were in a non-urban or metropolitan region. They were selected at random until we had recruited practitioners from 10 rural and 20 metropolitan regions. From August to December 2000, a researcher invited all women aged 16-50 years presenting for themselves or with relatives

Table 1 Characteristics of women attending general practice who had ever been in an intimate relationship as an adult compared with females in Australian population

\begin{tabular}{|c|c|c|}
\hline Characteristics & No $(\%)$ of participants ( $n=1257)$ & $\%$ of Australian population \\
\hline Marital status: & & $(n=4770532)^{\star}$ \\
\hline Never married & $263(21.1)$ & 28.5 \\
\hline Married & 721 (57.8) & 50.1 \\
\hline Defacto & $130(10.4)$ & NA \\
\hline Separated & $56(4.5)$ & 3.6 \\
\hline Widowed & $8(0.6)$ & 9.7 \\
\hline Divorced & $70(5.6)$ & 8.1 \\
\hline Age: & & $(\mathrm{n}=4772$ 167) \\
\hline 16-19 & $89(7.1)$ & 10.9 \\
\hline $20-29$ & $263(21.1)$ & 26.8 \\
\hline 30-39 & $455(36.5)$ & 30.3 \\
\hline $40-50$ & $439(35.2)$ & 32.1 \\
\hline Socioeconomic indext: & & $(\mathrm{n}=4772167)$ \\
\hline 10th centile & $47(3.9)$ & 10 \\
\hline 25th centile & $188(19.3)$ & 25 \\
\hline 50th centile & $320(45.7)$ & 50 \\
\hline 75th centile & $185(60.9)$ & 75 \\
\hline 90th centile & $475(100)$ & 90 \\
\hline Pregnant & $79(6.3)$ & NA \\
\hline Children cohabiting & $755(60.1)$ & NA \\
\hline Born in Australia & $1061(85.0)$ & $72 \ddagger$ \\
\hline English first language & 1179 (95.3) & $84.0 \S$ \\
\hline Aboriginals or Torres Strait islanders & $23(1.9)$ & $2.2 \ddagger$ \\
\hline Education level: & & $(n=6 \quad 664135)$ \\
\hline$<10$ years & $99(8.0)$ & 19.3 \\
\hline $10-12$ years & $577(46.4)$ & 38.1 \\
\hline Certificate or diploma & $239(19.2)$ & 25.6 \\
\hline Bachelor degree & $330(26.5)$ & 17.0 \\
\hline Employment status: & & $(n=6763900)$ १ \\
\hline Paid employment & $805(65.0)$ & 60.0 \\
\hline Not employed & $434(35.0)$ & 40.0 \\
\hline Yearly income (before tax): & & $(n=9354300)^{* *}$ \\
\hline$\leq \$ A 25999$ & $371(31.4)$ & 46.0 \\
\hline$\geq \$ A 26000$ & $812(68.6)$ & 54.0 \\
\hline \multicolumn{3}{|l|}{ Source of income: } \\
\hline Wage & 1017 (81.8) & $56.7 \dagger \dagger$ \\
\hline Pension or benefit & $168(13.5)$ & 28.0 \\
\hline Other & $59(4.7)$ & 15.3 \\
\hline Private health insurance & $752(60.7)$ & 44.8㧊 \\
\hline \multicolumn{3}{|c|}{ 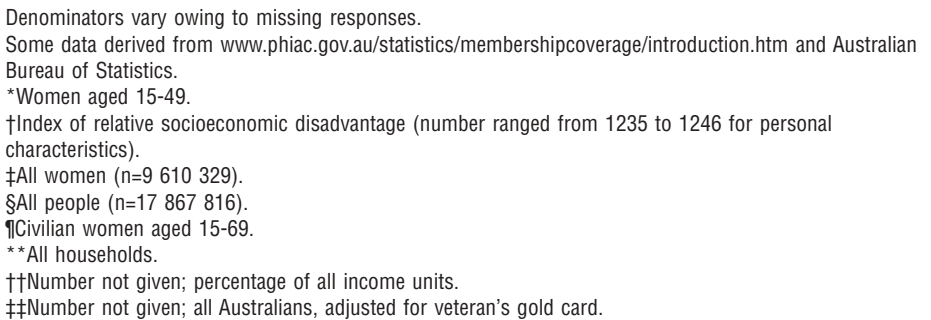 } \\
\hline
\end{tabular}

to complete a questionnaire. Women were excluded if they lacked the mental or physical capacity to answer the questionnaire, did not understand English, or attended with a male partner.

Our sample size calculation was based on published data. We estimated that we required 1084 women (power $80 \%$, significance level $5 \%$, two sided test) from 30 practices to detect a difference of $12 \%$ in the proportion of depressed women between those who had or had not been abused by a partner, assuming an intraclass correlation of 0.02 and a 20\% prevalence for depression and abuse. ${ }^{56}$

The questionnaire provided us with data on sociodemographic characteristics and lifetime abuse and history of partner abuse in the past 12 months using the composite abuse scale; depression was assessed with the Beck depression inventory or Edinburgh postnatal depression scale, and physical health was assessed with the SF-36. ${ }^{7-11}$ We converted the postcodes of the participants' current addresses into the index of relative socioeconomic disadvantage. ${ }^{12}$ Depression was defined as a Beck depression inventory score of 16 or more or an Edinburgh postnatal depression scale score of 12 or more. ${ }^{71{ }^{13}}$ A priori we hypothesised that partner abuse would be a strong predictor of depression.

Data were analysed with STATA version 7.0. We used bivariate analyses (adjusting for clustered data) to examine associations between women (who had ever been in an adult intimate relationship) identified as probably depressed or not depressed, with self report of ever abused, abused by a partner, abused as a child, composite SF-36 physical health score, and patient characteristics. Multivariate logistic regression was used to investigate the association between partner abuse and probable depression, adjusting for the other variables.

\section{Results}

We approached 39 eligible general practitioners. Five of these had moved practice and four refused to participate, giving a response rate of $77 \%$. Participants differed from the Australian general practitioner population in that more were female $(18,60 \%)$, worked part time $(13 / 27,48 \%)$, and had graduated recently $(17,59 \%)$.

Overall, $133(7.0 \%)$ female patients had previously attended and 141 of 1896 patients aged 16-50 years were excluded because they were accompanied by a partner (62), were too ill (31), had comprehension or motor problems (22), were non-English speakers (16), or had difficulty seeing or hearing (10). Overall, 1257 $(77.5 \%)$ eligible women completed the questionnaire, $66(4.1 \%)$ were missed, and 299 (18.4\%) refused. Most of the 1257 patients attended for themselves (868, $69.1 \%)$ and $1210(96.3 \%)$ had been in an adult intimate relationship (table 1). When we compared the quintile percentages of index of relative socioeconomic disadvantage, fewer women were represented with the combination of low income, limited training, and unskilled occupations.

\section{Prevalence}

Depression

On a general question about depression, 543 of 1227 $(44.3 \%)$ women reported ever experiencing depression 
lasting more than two weeks. Most (417, 76.8\%) had ever told a general practitioner about that depression, of which two thirds $(273,65.5 \%)$ had told the participating general practitioner. For current mood (last week), 218 of 1213 (17.9\%) women scored as probably depressed on the Beck depression inventory or Edinburgh postnatal depression scale.

\section{Abuse by partner}

One third (437/1173, 37.3\%) of participants who had ever been in an adult intimate relationship stated that they had ever experienced some form of abuse. One third of these $(142 / 417,34 \%)$ had ever told a general practitioner about that abuse, of which one third $(49 / 140,35 \%)$ had told the participating general practitioner, and one in five $(81 / 411,20 \%)$ had ever been asked by a general practitioner. One quarter (277/ $1147,24.1 \%$ ) of participants scored as having experienced some type of abuse on the composite abuse scale in the past 12 months of a current or previous relationship. Severe combined abuse was experienced by $8.8 \%$ (101) of women, physical and emotional abuse or harassment by $5.7 \%$ (65), physical abuse alone by $7.1 \%$ (82), and emotional abuse or harassment alone by $2.5 \%(29)$.

\section{Association with depression}

Compared with women who were not depressed, those who scored in the probably depressed range were more likely to be unmarried, on a pension or low income, receiving benefits, unemployed, or to have had a poorer education (table 2). Probably depressed women were much more likely to have experienced some form of abuse (physical, emotional, or sexual) as a child (odds ratio $3.0,95 \%$ confidence interval 2.1 to $4.2)$, and this remained significant (2.0, 1.3 to 2.9 ) when adjusted for sociodemographic variables, physical health (SF-36), and intimate partner abuse as an adult. Furthermore, probably depressed women were more likely to have experienced partner abuse, particularly severe combined abuse (8.0, 4.8 to 13.0) and physical and emotional abuse or harassment (8.1, 4.4 to 15.0 ; table 2). Even when these values were adjusted for all other variables, multidimensional measures of partner abuse remained highly associated with probable depression, with the magnitude of the effect being large (table 2).

Table 2 Association between probable depression and abuse by partner, abuse as a child, and sociodemographic factors for women attending general practice who had ever been in an intimate relationship as an adult $(n=1210)$. Values are numbers (percentages) unless stated otherwise

\begin{tabular}{|c|c|c|c|c|}
\hline Characteristic & Probably depressed & Not depressed & Odds ratio $(95 \% \mathrm{CI})$ & Adjusted odds ratio ( $95 \% \mathrm{Cl})$ \\
\hline Total & $207(17.6)$ & $966(82.4)$ & - & - \\
\hline Ever abused ${ }^{\star}$ & $130(65.0)$ & $298(31.6)$ & $4.0(3.0$ to 5.5$)$ & - \\
\hline \multicolumn{5}{|l|}{ Type of abuse†: } \\
\hline None & $91(46.7)$ & 758 (81.9) & 1 & 1 \\
\hline Severe combined & $48(24.6)$ & $50(5.4)$ & $8.0(4.8$ to 13$)$ & $5.8(2.8$ to 12$)$ \\
\hline Physical and emotional or harassment & $32(16.4)$ & $33(3.6)$ & 8.1 (4.4 to 15$)$ & $7.5(3.9$ to 14$)$ \\
\hline Physical only & $8(4.1)$ & $21(2.3)$ & $3.2(1.58$ to 6.4$)$ & $3.5(1.7$ to 7.2$)$ \\
\hline Emotional or harassment & $16(8.2)$ & $63(6.8)$ & 2.1 (1.07 to 4.2$)$ & 2.1 (0.99 to 4.3$)$ \\
\hline Abused as child $\ddagger$ & $98(49.2)$ & $231(24.4)$ & $3.0(2.1$ to 4.2$)$ & $2.0(1.3$ to 2.9$)$ \\
\hline \multicolumn{5}{|l|}{ Age (years): } \\
\hline $16-20$ & $23(11.1)$ & $59(6.1)$ & 1.7 (0.93 to 3.1$)$ & $1.9(0.85$ to 4.1$)$ \\
\hline $21-30$ & $51(24.6)$ & $210(21.9)$ & 1.1 (0.70 to 1.6$)$ & 1.2 (0.61 to 2.2$)$ \\
\hline $31-40$ & $63(30.4)$ & $386(40.2)$ & $0.71(0.51$ to 1.0$)$ & 0.95 (0.53 to 1.7$)$ \\
\hline $41-50$ & $70(33.8)$ & $306(31.8)$ & 1 & 1 \\
\hline \multicolumn{5}{|l|}{ Marital status: } \\
\hline Married or defacto & $108(52.2)$ & $714(74.1)$ & 1 & 1 \\
\hline Never married or single & $53(25.6)$ & $166(17.2)$ & $2.1(1.4$ to 3.2$)$ & $1.0(0.56$ to 2.0$)$ \\
\hline Separated, widowed, or divorced & $46(22.2)$ & $84(8.7)$ & $3.6(2.3$ to 5.6$)$ & 1.2 (0.63 to 2.3$)$ \\
\hline \multicolumn{5}{|l|}{ Education level: } \\
\hline Certificate, diploma, bachelor degree or higher & $77(37.4)$ & $480(49.9)$ & 1 & \\
\hline Completed year 10 or $12 \S$ & $97(47.1)$ & $422(43.9)$ & $1.4(1.1$ to 1.9$)$ & $1.2(0.78$ to 1.8$)$ \\
\hline Left school before year 10 & $32(15.5)$ & $60(6.2)$ & $3.3(2.1$ to 5.3$)$ & $2.6(1.5$ to 4.4$)$ \\
\hline Not in paid employment & $92(44.7)$ & $306(31.9)$ & $1.7(1.2$ to 2.4$)$ & $1.2(0.72$ to 1.9$)$ \\
\hline \multicolumn{5}{|l|}{ Income source: } \\
\hline Pension or benefit & $60(29.3)$ & $97(10.1)$ & $3.7(2.5$ to 5.5$)$ & $1.3(0.68$ to 2.4$)$ \\
\hline Wages, salary, or other & $145(70.7)$ & $867(89.9)$ & 1 & 1 \\
\hline \multicolumn{5}{|l|}{ Total yearly income (before tax): } \\
\hline$\leq \$ A 25999$ & $101(51.5)$ & $240(26.0)$ & $3.0(2.3$ to 4.0$)$ & - \\
\hline$\geq \$ A 26000$ & 95 (48.5) & $684(74.0)$ & 1 & - \\
\hline Pregnant & $6(2.9)$ & $71(7.4)$ & $0.38(0.14$ to 1.0$)$ & 0.21 (0.08 to 0.55$)$ \\
\hline Children (<16 years) cohabiting & $114(55.1)$ & $614(63.7)$ & $0.70(0.51$ to 1.0$)$ & 0.64 (0.38 to 1.1$)$ \\
\hline Postnatal & $15(7.2)$ & $69(7.1)$ & $1.0(0.62$ to 1.7$)$ & $1.5(0.82$ to 2.8$)$ \\
\hline Mean SF-36 (SD) health score & $46.3(11.9)$ & $49.8(9.2)$ & 0.97 (0.95 to 0.99$)$ & $0.98(0.95$ to 1.00$)$ \\
\hline
\end{tabular}

$£ 1.00(\$ 1.84 ; € 1.52)$

Denominators vary due to missing responses. All listed variables adjusted for in multivariate analysis except for ever abused and total yearly income as they were highly correlated with current partner abuse and source of income, respectively.

*37 women did not have a response for depression.

tComposite abuse scale.

‡Physical, emotional, or sexual.

§Year 10 pupils are aged 15 or 16 and year 12 pupils are aged 17 or 18 


\section{What is already known on this topic}

The association between depression and partner abuse is strong for women

Limited data are available from studies in primary care

Most studies have concentrated on physical violence

\section{What this study adds}

Physical, emotional, and sexual abuse is a strong predictor of probable depression

Researchers should measure partner abuse in longitudinal and intervention depression studies

Doctors should consider partner abuse in women with depression

\section{Discussion}

The association between depression and abuse by a partner in women presenting to their general practitioners is significant even after adjustment for social indicators associated with depression. ${ }^{1}$ This confirmed the findings from other settings of women experiencing current or past abuse by a partner. ${ }^{2}{ }^{14} 15$ Although we cannot infer causation, we have some evidence that partner abuse may contribute to depression rather than the opposite. ${ }^{1}$

Our study is the first to look at the association between depression and types of abuse (emotional, physical, sexual) for women attending a variety of general practices. We recruited 30 general practitioners from practices with an $18 \%$ prevalence for depression and $24 \%$ prevalence for abuse, similar to other general practitioner samples using the same instruments. ${ }^{5}{ }^{6}$

Limitations of our study include the use of self report to measure outcomes and the cross sectional design, which precludes a causal inference. Literature on depression has largely ignored evaluating the differences between the sexes in response to treatments and the role of partner abuse as a contributing factor in persistence or relapse of depression..$^{16-18}$ Untangling the nature of the association requires longitudinal studies, and researchers in depression should consider measuring partner abuse. In treating women who are depressed, doctors should be alert to the possibility of abuse and the lack of evidence about the effectiveness of depression interventions for women experiencing abuse. Ignoring the part partner abuse plays in depression reinforces the hidden nature of this issue for women. ${ }^{19}$

We thank Nancy Carabella, Christina Pitter, and Jacinta Lee who administered the project; the general practitioners and women who participated; Cate Nagle who helped with coding; the research assistants who collected the data (Tessa Keegal, Deidre Harrison, Desiree Green, Amanda Webb, Caroline Curtis, Colleen Nordstrom, Ann Vlass, Sally Ann Avery, Elke Varga, and Prue Forbes); the Women's Health in General Practice research group (University of Melbourne); Vanessa Madden who reviewed the final draft; and Peter Rose (Oxford University) for editing.
Contributors: $\mathrm{KH}$ designed the study and drafted and led revision of the paper assisted by JG, $\mathrm{PC}$, and $\mathrm{RS}$. $\mathrm{KH}$ will act as guarantor for the paper. JG and RS helped design the study and interpret the data. PC analysed and interpreted the data. The guarantor accepts full responsibility for the conduct of the study, had access to the data, and controlled the decision to publish.

Funding: This project was funded by the Department of Health, Housing and Community Services, Canberra, Australia through the General Practice Evaluation Program.

Competing interests: None declared.

Ethical approval: This study was approved by the human ethics committee, University of Melbourne.

1 Astbury J, Cabral M. Women's mental health: an evidence based revieu. Geneva: World Health Organization, 2000

2 Golding J. Intimate partner violence as a risk factor for mental disorders: a meta-analysis. J Fam Violence 1999;14:99-132.

3 Coid J, Petruckevitch A, Chung W, Richardson J, Feder G. Abusive experiences and psychiatric morbidity in women primary care attenders. $\mathrm{Br} J$ Psychiatry 2003;183:332-9.

4 McCauley J, Kern DE, Kolodner K, Smith J. The "battering syndrome" prevalence and clinical characteristics of domestic violence in primary care internal medicine practices. Ann Intern Med 1995;123:737-46.

5 Hegarty K, Bush R. Prevalence of partner abuse in women attending Australian general practice: a cross-sectional survey. Austr NZ J Public Health 2002;26:437-42.

6 Katon W, Schulberg H. Epidemiology of depression in primary care. Gen Hosp Psychiatry 1992;14:237-47.

7 Hegarty, KL, Sheehan M, Schonfeld C. A multidimensional definition of partner abuse: development and preliminary validation of the composite abuse scale. J Fam Violence 1999;14:399-414

8 Dowrick C. Does testing for depression influence diagnosis or management by general practitioners? Fam Pract 1995;12:461-5.

9 Cox JL, Holden JM, Sagovsky R. Detection of postnatal depression. Development of the 10-item Edinburgh postnatal depression scale. $\mathrm{Br} \mathrm{J}$ Psychiatry 1987;150:782-6.

10 Boyce P, Stubbs J, Todd A. The Edinburgh postnatal depression scale: validation for an Australian sample. Austr NZ J Psychiatry 1993;27:472-6.

11 McHorney CA, Ware JE, Lu JFR, Sherbourne CD.The MOS 36-item short form health survey (SF-36): III. Tests of data quality, scaling assumptions and reliability across diverse patient groups. Med Care 1994;32:40-66.

12 Castles I. Information paper 1991 census: socio-economic indexes for areas. Canberra, Australia: Australian Bureau of Statistics, 1991

13 Murray L, Carothers AD. The validation of the EPDS on a community sample. Brit J Psychiatry 1990;157:288-90.

14 Campbell J. Health consequences of intimate partner violence. Lancet 2002;359:1331-6.

5 Roberts GL, Williams GM, Lawrence JM, Raphael B. How does domestic violence effect women's mental health? Wom Health 1998;28:117-29.

16 MacGillvray S, Arrol B, Hatcher S, Ogston S, Reid I, Sullivan F. Efficacy and tolerability of selective serotonin inhibitors compared with tricyclic and tolerability of selective serotonin inhibitors compared with tricyclic antidepressants in depression treated in $\mathrm{p}$

17 Van Weel-Baumgarten, E, Schers H, van den Bosch WJ, van den Hoogen $\mathrm{H}$, Zitman FG. Long-term follow-up of depression among patients in the community and in family practice settings: a systematic review.J Fam Pract 2000;49:1113-20.

18 Herrman, H, Patrick D, Diehr P, Martin M, Fleck M, Simon G. Longitudinal investigation of depression outcomes in primary care in six countries: the LIDO study. Functional status, health service use and treatment of people with depressive symptoms. Psychol Med 2002;32:889-902.

19 Jewkes R. Intimate partner violence: causes and prevention. Lancet 2002;359:1423-9.

(Accepted 20 February 2004)

\section{bmjlearning.com}

\section{Post-traumatic stress disorder}

About 1 in 10 women and 1 in 20 men get post-traumatic stress disorder at some point in their lives. The risk is high in soldiers and in refugees who have fled from war, torture, or "ethnic cleansing." Up to $80 \%$ of patients with post-traumatic stress disorder have a concurrent psychiatric disorder. Making a diagnosis is important because post-traumatic stress disorder is treatable. To find out more, take the new learning modules on the diagnosis and treatment of post-traumatic stress disorder on bmjlearning.com 